\title{
Discrimination gradients in human eyelid conditioning
}

WILLIAM F. PROKASY, CHARLES K. ALLEN, and MUKUL K. DEY, University of Utah, Salt Lake City, Utah 84112

Human Ss were given five 360 differential conditioning trial sessions with one CS+ and six $C S-s$. The independent variable was left-most, center, or right-most light in a seven-light array as the CSt. Individual gradients were stable and changed little following the first session. Sequential reinforcement and nonreinforcement effects were observed for the $C S-s$, but not the CSt. Also, there was no evidence that closer physical proximity of $C S-s$ depressed $C S+$ performance.

The object of this study was to determine (1) if stable individuatS discrimination gradients could be obtained in human eyelid conditioning, (2) if there were any long-term sequential effects of reinforcement and nonreinforcement in differential conditioning, and (3) if a relevant dimension, spatial separation of $\mathrm{CS}-$ and $\mathrm{CS}+$, affected performance as would be predicted from an excitation-inhibition gradient theory of differential conditioning (Spence, 1936).

\section{APPARATUS}

The basic apparatus for transducing and recorded has been reported by Prokasy, Carlton, \& Higgins (1967). CS+ and CSwere changes in brightness of .75-in. diam red cut-glass jewel lighted from behind by a $7.5 \mathrm{~W}$ bulb. There were seven such stimuli at a distance of approximately $60 \mathrm{in}$. in front of S, mounted horizontally, with a spatial separation of $2.5 \mathrm{in}$. between centers of adjacent stimuli. The UCS was a $50-\mathrm{msec}$ puff of $\mathrm{N}$ to $\mathrm{S}$ 's right comea, and of sufficient intensity to support a $150-\mathrm{mm}$ column of mercury. CS+ and CS-duration were $500 \mathrm{msec}$, and the UCS occurred at the offset of CSt.

\section{SUBJECTS}

The Ss were 49 students from introductory psychology courses at the Pennsylvania State University.

\section{PROCEDURE}

The independent variable was location of CSt. For 13 Ss CS+ was the left-most (Group L), for 24 Ss CS+ was the center (Group C), and for $12 \mathrm{Ss}$ CSt was the right-most of the seven-light display. All Ss were given five sessions of 360 trials each. One hundred twenty trials were to CS+ and 240 trials were divided equally among the six CS-s. Order of presentation was random with the restriction that the proportions of $\mathrm{CS}+$ and $\mathrm{CS}-\mathrm{s}$ were corrected within each of two blocks of 180 trials. A CR was defined as a pen movement of at least $1 \mathrm{~mm}$ in the interval from 148 to $524 \mathrm{msec}$ after CS onset. The intertrial interval averaged $10 \mathrm{sec}$.

\section{RESULTS AND DISCUSSION}

There was little change in individual-S gradients across sessions. The gradients stabilized during the first session and did not reliably sharpen across the remaining sessions. They were sufficiently alike from $S$ to $S$ within each of the three groups that the mean gradients shown in Fig. 1, and collapsed across all 1800 trials, are reasonably representative of individual-S gradients on a session-by-session basis.

Figure 1, however, provides additional information. In each of the three subfigures are two curves. The lower curve is response probability to a particular stimulus given that the preceding trial was not reinforced (i.e., that one of the six CS-s was presented). The upper of the two is response probability to a particular stimulus given that the preceding trial was reinforced (i.e., that CS+ occurred).

The first question is whether or not there is a discrimination gradient other than the large drop in probability from $\mathrm{CS}+$ to an adjacent CS-. All 13 Ss in Group L, and all 12 in Group R, gave higher mean probabilities to the CS- adjacent to the CS+ than to the CS- furthest away from CS,$+ x^{2}(1)=13.0$ and 12.0 , respectively. Similarly, 22 of the 24 Ss in Group $C$ had a higher response probability to the CS- adjacent to the CS+ than their average to the $\mathrm{CS}-\mathrm{s}$ furthest removed from $\mathrm{CS}+$, $\chi(1)=16.7$. Thus, the spatial separation of stimuli is a relevant dimension in this situation. Moreover, responding to the most remote CS - is above the chance level. This is determined from the fact that for Group $C$ and Groups $L$ and $R$ combined, 20 and $19 \mathrm{Ss}$, respectively, responded more following a CS+ than following a $\mathrm{CS}-, x^{2}(1)=10.7$ and 6.5 , respectively.

Despite the fact that response probability to each CS- was greater following a reinforced rather than a nonreinforced trial, a similar effect was not obtained with the CS+. A total of only 13 of the $25 \mathrm{Ss}$ in Groups $\mathrm{L}$ and R combined, and only 8 of 24 in Group C, exhibited a higher response probability to CS+ following a CSt, rather than a CS-, trial. This outcome is consistent with that reported by Prokasy, Higgins, \& Carlton (1968): with sequences of CSt, response probability did not increase following the first (but did following the next) CS+. Since the present study was conducted with 1800 trials per $S$, and the Prokasy et al study employed 360 trials per S, the

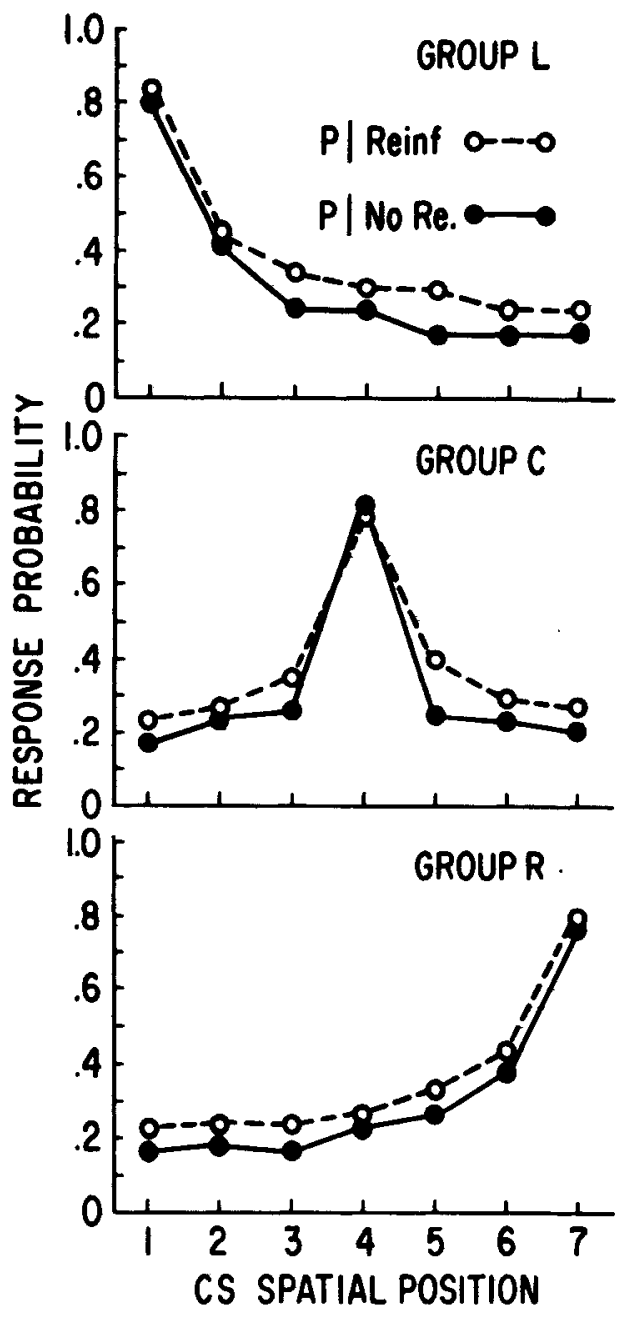

Fig. 1. Response probability to each of the seven stimuli, collapsed across all 1800 trials, as a function of whether the preceding trial was or was not a CS+ trial. 
failure to obtain a reinforcement effect following the first in a series of CS+ trials seems to be a pervasive characteristic of differential eyelid conditioning. The problem these data pose is that an unmodified linear-operator model of differential conditioning (e.g., Bush \& Mosteller, 1951) is unable to account for it. The CS+ effect is particularly puzzling in view of the fact that in this study, as well as in that of Prokasy et al, the anticipated decremental effect of a nonreinforced trial was obtained.

If an excitation-inhibition theory of differential conditioning (Spence, 1936) is to account for the data, then it would be predicted that response probability to CS+ in Group $C$ would be less than that in Groups $L$ and $R$ combined. This would be expected because the mean distance of the nonreinforced stimuli from CS+ is less in Group C than in either of the other two Groups. As Fig. 1 suggests, responding to CS+ did not differ reliable between Group $\mathrm{C}$ and Groups $\mathrm{L}$ and $R, F(1,47)=.03$. While we cannot accept the null hypothesis, the facts that the spatial gradient has been shown to be a relevant dimension and that sequential effects were manifested to the CS- stimuli show that transfer effects do exist. The transfer effect from CS- to CS+ was apparently limited and not a function of spatial separation.

Both the linear operator model of Bush \& Mosteller (1951) and the Spence theory of differential conditioning (1936) have in common a prediction that in differential conditioning response probability will increase following a CS+ trial and decrease following a CS - trial. Similarly, the incremental and decremental effects should vary inversely as a function of stimulus discriminability. The failure to find an incremental effect following the first in a sequence of CSts and the failure for physical separation of stimuli to have a differential effect on responding to $\mathrm{CS}+$ despite a demonstrated discrimination gradient indicates that additional assumptions will be necessary to account for the fine-grain detail of differential classical eyelid conditioning.

\section{REFERENCES}

BUSH, R. R., \& MOSTELLER, F. A model for stimulus generalization and discrimination. Psychological Review, 1951, 58, 413-423.

PROKASY, W. F., CARLTON, R. A., \& HIGGINS, J. D. Effects of nonrandom intermittent reinforcement schedules in human eyelid conditioning. Journal of Experimental Psychology, 1967, 74, 282-288.

PROKASY, W. F., HIGGINS, J. D., \& CARLTON, R. A. Sequential effects in differential human eyelid conditioning. Psychonomic Science, 1968, 12, 5.

SPENCE, $K$. W. The nature of discrimination learning in animals. Psychological Review, 1936, 43, 427-449.

$$
\text { NOTE }
$$

1. This research was supported by Grants GB-3875 and GB-6750 to William F. Prokasy from the National Science Foundation. Charles K. Allen was a NIMH Postdoctoral Research Fellow and Mukul Dey was a participant in a program of Research Participation for College Teachers, supported by a grant from the National Science Foundation to William M. Lepley.

\begin{tabular}{|c|c|c|}
\hline $\mathrm{KRT}$ & $.0_{4}$ & BRD \\
\hline LTF & .04 & FSN \\
\hline KKKT & .04 & CLT \\
\hline $\mathrm{H} H \mathrm{~N}$ & .05 & CPR \\
\hline ITN & .05 & GDN \\
\hline NLT & .05 & IPC \\
\hline TFN & .05 & $\operatorname{SC} X$ \\
\hline NGR & .05 & $\operatorname{IRC}$ \\
\hline JLP & .06 & CNT \\
\hline KRG & .06 & $\mathrm{CHH}$ \\
\hline PKL & .06 & PIN \\
\hline${ }^{n} \mathrm{NH}$ & .06 & $\mathrm{BPD}$ \\
\hline TILC & .07 & PDG \\
\hline SitD & .07 & GCT \\
\hline JUS & .08 & PDI \\
\hline RLXX & .08 & \\
\hline BLR & .09 & 67 \\
\hline IKD & .09 & $\mathrm{THR}$ \\
\hline NDS & .09 & $\mathrm{HDR}$ \\
\hline $\mathrm{NHF}$ & .09 & MWS \\
\hline RBI & .09 & THL \\
\hline DNH & .10 & BHS \\
\hline HSM & .10 & PHN \\
\hline $\mathrm{BS}$ & .11 & DHR \\
\hline $\mathrm{Br}^{2}$ & .12 & KPS \\
\hline ClAR & .13 & IDS \\
\hline KNP & .13 & MLH \\
\hline PKJI & .13 & HIFR \\
\hline SHD & .13 & YDR \\
\hline $\mathrm{NCA}$ & .14 & DHS \\
\hline$S Q D$ & .14 & RPL \\
\hline TNQ & .17 & DNS \\
\hline क्H & .19 & $\mathrm{RKC}$ \\
\hline PUB & .20 & SinL \\
\hline CGR & .21 & .HS \\
\hline $\mathrm{RD}^{\prime \prime}$ & .22 & iRL \\
\hline ZSK & .23 & LGR \\
\hline PGL & .24 & PBL \\
\hline LIDP & .25 & CSH \\
\hline$D G r$ & .28 & HSC \\
\hline $\mathrm{GDR}$ & .28 & $i r S x$ \\
\hline
\end{tabular}

XPD .23

PGN .27

DGN .32

Fis . 32

SCP .33

CFT . 34

IPP . 34

FNT . 35

PTG . 59

$\frac{71 \% \text { AV }}{B R \times 1}$

FDR .03

RWH .03

JRD . 04

NTR . 04

PFL . 04

BSN .05

HRK .05

FRC . 06

FRK . 06

KGR .06

KSP .06

KIDR .06

Rivis .06

$\mathrm{C.XX} .07$

INL .08

TRL .08

HQS .10

2SH .10

HLS .11

JGL .11

KJIP .11

$\mathrm{aKN} \cdot 11$

HCH .12

HDS .13

KNF .13

IIRG .13

SLC .14

NCL . 16

NSC .19
(Continued from page 190)

\begin{tabular}{|c|c|c|}
\hline TBL & .19 & FLS \\
\hline TMR & .19 & PHT \\
\hline FTB & .20 & $\mathrm{TCH}$ \\
\hline CGS & $.24_{4}$ & MIP \\
\hline$S P$ & .24 & $\mathrm{MPT}$ \\
\hline GLB & .27 & PTH \\
\hline$D C$ & .28 & SHF \\
\hline
\end{tabular}

IGD .28

$\mathrm{BGN} .29$

DAB .32

NDG .32

PKC $: 33$

$75 \mathrm{FAV}$

PRX .01

BKS . $\alpha_{4}$

BSK.$\alpha_{4}$

ins . $\mathrm{O}_{4}$

BRM . 06

HIN .06

KFT .06

IIRD .06

NBL .06

FLN .08

DRL .09

HPS .09

IND .09

SHV .09

IHX . 10

CLR .11

RCH .11

IKN .12

IGN .12

HIKS .13

GLN .14

BMP . 20

RTD .22

ING . 22

GLP . 24

PKD .26

HiDG . 30

\begin{tabular}{|c|c|c|c|c|c|}
\hline WDS & .07 & DFT & .23 & MSK & .11 \\
\hline CRL & .11 & SPD & .23 & ITNK & 1 \\
\hline$S Q B$ & .11 & PRC & .32 & RNG & • \\
\hline GWN & .12 & PCK & .36 & KNG & \\
\hline HNK & .13 & & & GRD & 2 \\
\hline $83 \%$ & CAV & $88 \%$ & AAV & DBI & \\
\hline BKR & .03 & SPN & .03 & & \\
\hline HTL & .03 & Stin & $v_{4}$ & & \\
\hline PHL & .03 & FNT & .05 & $96 \%$ & 61 \\
\hline RHF & .03 & GLW & .05 & TWN & \\
\hline $\mathrm{HQ}$ & .04 & HRN & .05 & FLP & \\
\hline ins & .04 & SLD & .06 & LFT & - \\
\hline FWN & .05 & SNG & .13 & $\overline{D S H}$ & .7 \\
\hline MRW & .05 & $\mathrm{KCH}$ & .15 & GRN & \\
\hline BLW & .06 & BLT & .19 & BND & \\
\hline HNT & .06 & $\mathrm{BXT}$ & .19 & FSK & $\bullet$ \\
\hline JLT & .06 & PRD & .22 & & \\
\hline IRD & .06 & THD & .24 & & \\
\hline VLD & .07 & DRG & .28 & & \\
\hline JRN & .09 & PNT & .34 & & \\
\hline MiRK & .11 & & & 100 & $O_{0}^{1} A$ \\
\hline CRM & .13 & $9 x_{i}$ & AV & DRK &. \\
\hline GLR & .13 & $W R$ & .01 & Sind & .0 \\
\hline SFIK & .13 & IHR & .03 & PNK & .1 \\
\hline B'TH & .21 & MBR & .06 & SNK & .1 \\
\hline DPR & .22 & SHP & .09 & $\mathrm{DNT}$ & .2 \\
\hline $\mathrm{IGR}$ & .22 & $\because N D$ & .10 & $\mathrm{DPT}$ & \\
\hline
\end{tabular}

REFERENCES

CLARKE, F. R. Constant ratio rule for confusion matrices in speech communication. Journal of the Acoustical Society of America, 1957, 29, 715-720.

CONRAD, R. Acoustic confusions in immediate memory. British Jou rnal of Psychology, 1964, 55, 75-84.

WICKELGREN, W. A. Short-term memory for phonemically similar lists. American Journal of Psychology, 1965, 78, 567-574.

WITMER, L. The Association Value of three-place consonant syllables. Journal of Genetic Psychology, 1935, 47, 337-359.

$$
\text { NOTE }
$$

1. The computer facilities used in this work were made available through grants from the Science Research Council. The authors are grateful to the Medical Research Council for financial support. 